\title{
The Visual Dictionary of Antimicrobial Stewardship, Infection Control, and Institutional Surveillance
}

Julia Keizer ${ }^{1 *}$, Christian F. Luz ${ }^{2 *}$, Bhanu Sinha ${ }^{2}$, Lisette van Gemert-Pijnen ${ }^{1}$, Casper Albers ${ }^{3}$, Nienke Beerlage-de Jong ${ }^{4 \dagger}$, Corinna Glasner ${ }^{2 \dagger}$

1 University of Twente, Department of Psychology, Health and Technology, Centre for eHealth and Wellbeing Research, PO box 217, 7500AE Enschede, The Netherlands

2 University of Groningen, University Medical Center Groningen, Department of Medical Microbiology and Infection Control, Hanzeplein 1, 9700RB Groningen, The Netherlands

3 University of Groningen, Heymans Institute for Psychological Research, Grote Kruisstraat 2/1, 9712 TS Groningen, The Netherlands

4 University of Twente, Department of Health Technology and Services Research, Technical Medical Center, Faculty of PO box 217, 7500AE Enschede, The Netherlands

${ }^{*, \dagger}$ Equal contribution 


\section{Abstract}

\section{Objectives}

Data and data visualization are integral parts of (clinical) decision-making in general and stewardship (antimicrobial stewardship, infection control, and institutional surveillance) in particular. However, systematic research on the use of data visualization in stewardship is lacking. This study aimed at filling this gap by creating a visual dictionary of stewardship through an assessment of data visualization in stewardship research.

\section{Methods}

A random sample of 150 data visualizations from published research articles on stewardship were assessed. The visualization vocabulary (content) and design space (design elements) were combined to create a visual dictionary. Additionally, visualization errors, chart junk, and quality were assessed to identify problems in current visualizations and to provide improvement recommendations.

\section{Results}

Despite a heterogeneous use of data visualization, distinct combinations of graphical elements to reflect stewardship data were identified. In general, bar $(n=54 ; 36.0 \%)$ and line charts $(n=42$; $28.1 \%$ ) were preferred visualization types. Visualization problems comprised colour scheme mismatches, double y-axis, hidden data points through overlaps, and chart junk. Recommendations were derived that can help to clarify visual communication, improve colour use for grouping/stratifying, improve the display of magnitude, and match visualizations to scientific standards.

\section{Conclusions}

Results of this study can be used to guide data visualization creators in designing visualizations that fit the data and visual habits of the stewardship target audience. Additionally, the results can provide the basis to further expand the visual dictionary of stewardship towards more effective visualizations that improve data insights, knowledge, and clinical decision-making. 


\section{Introduction}

The amount of and reliance on data increases with the increase of scientific publications and information technologies in healthcare practice $[1,2]$. The increased complexity of big data raises various issues to be resolved by innovative big data analytics. This includes integrating, analysing and visualizing data to translate into meaningful information [3,4]. Translating raw data into meaningful information and communicating it to specific target groups is a challenge [1]. Without this translation and communication, researchers and practitioners cannot optimally use the information, so that the true value of the data remains hidden. Data visualization, here defined as the graphical representation of quantitative information, can facilitate the transformation, memorisation, and communication of data to understandable and actionable information. Data visualization also aids in the interpretation of increasingly large and complex datasets (big data) and in the understanding of sophisticated statistical models (machine learning) and their results - two rising trends over the last decades [5,6]. The importance of data visualization can, once again, be observed in the COVID-19 pandemic with the ubiquitous presence of charts, figures, and dashboards that aim to inform and support decision-making for a wide variety of target audiences [7].

Data visualization is a very active (research) field in itself and is generally part of typical statistical software used in the data analysis process (e.g. R, SPSS, SAS, STATA, Excel). Information and recommendations for the data visualization process are numerous and can be transferred between research fields or domains [8-11]. However, research on the visual domain context within a research field is often lacking, i.e. what the target audience is accustomed to see and expects in terms of content and design, and how this influences the perception and interpretation of data visualizations from different perspectives [12]. Common data visualization practices in a specific domain can be identified by studying the visualization design space [13]. This visual design space can be described as "an orthogonal combination of two aspects", namely marks (i.e. graphical elements such as points, lines and areas) and visual channels to control their appearance (i.e. aesthetic properties such as colour, size and shape) [13].

To clarify the conceptual definitions for assessing and describing data visualizations a linguistic analogy can be used: a dictionary describes language in terms of both vocabulary (i.e. the set of words familiar in a language) and grammar/punctuation (i.e. the set of structural rules and supporting marks that control the composition and navigability of sentences, phrases, and words). Similarly, the visual dictionary describes visualizations in terms of both visual vocabulary (i.e. the domain content in terms of visualized data attributes) and visual 
bioRxiv preprint doi: https://doi.org/10.1101/2021.05.19.444819. this version posted May 20, 2021. The copyright holder for this preprin (which was not certified by peer review) is the author/funder, who has granted bioRxiv a license to display the preprint in perpetuity. It is made available under aCC-BY 4.0 International license.

design space (i.e. graphical elements and supporting aesthetic properties). The language or visual domain context is an overarching concept that represents language/visualization in practice, i.e. expectations and customs of the target audience, and how this affects their perception and interpretation of data visualizations (see also Figure 1). The visual domain context is, just as language, subject to changes over time and subject to interpretation differences based on varying perspectives.

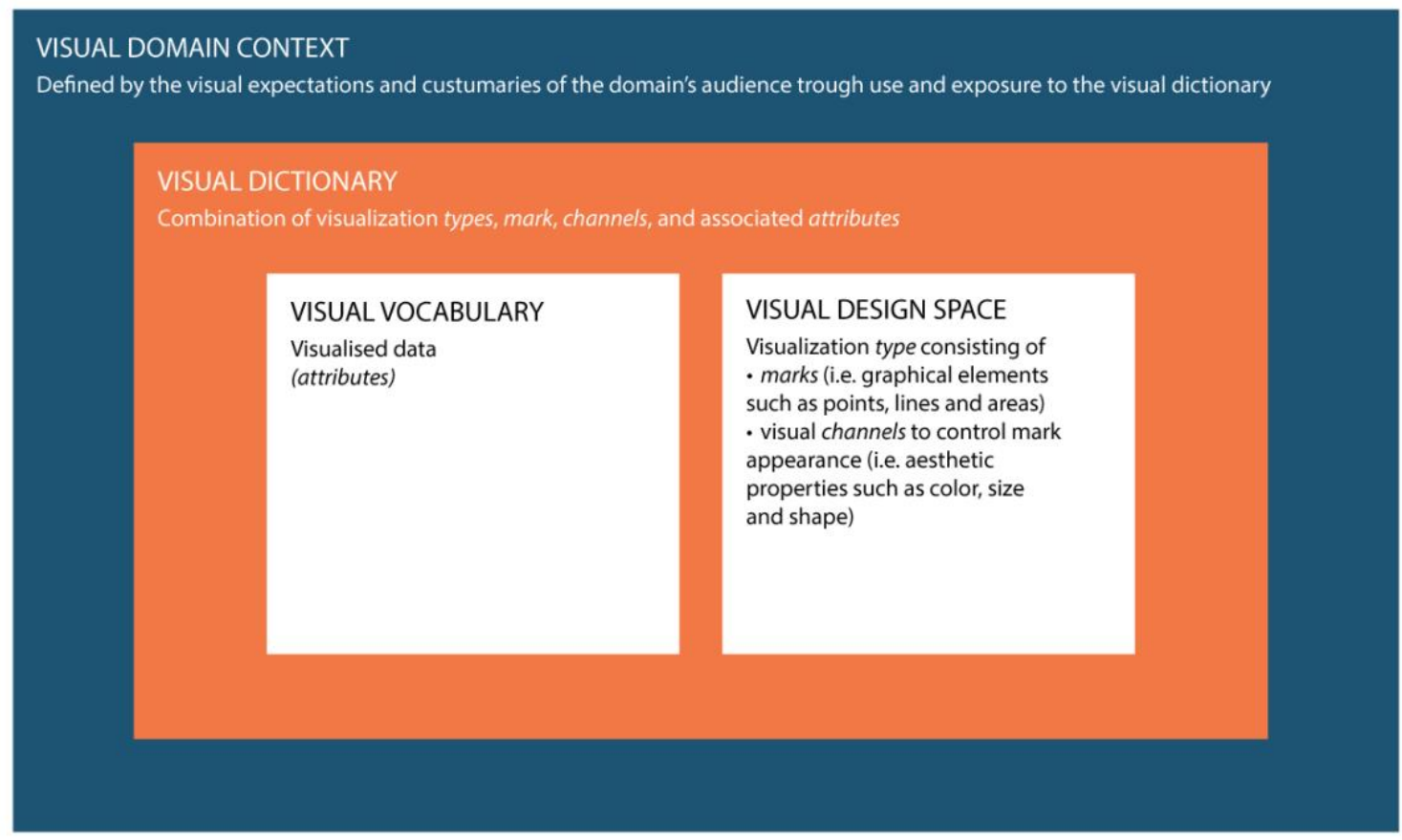

Figure 1. Conceptual framework used in this study to clarify the definitions and interrelations between the visual domain context, the visual dictionary and the visual domain vocabulary and visual design space.

Data and data visualization play important parts in the field of infectious diseases and antimicrobial resistance (AMR) for the reporting on the growing burden on health and healthcare systems $[14,15]$. Comprehensible and actionable information on antimicrobial consumption, pathogen distribution, or incidence and prevalence of (multi-) drug resistant microorganisms are vital to design interventions to tackle the AMR challenge [16]. On the hospital level, antimicrobial and diagnostic stewardship, infection control, and institutional surveillance (further summarised under 'stewardship') are the core components of strategies that promote the responsible use of antimicrobials and improve the quality and safety of patient care [17,18]. Data visualization is an integral part of these strategies, as it unveils the local situation and the drivers of AMR and can have a significant impact on the use of antimicrobials $[19,20]$. 
It has been shown how important it is to study data and data visualization experiences and perceptions in the medical domain and how this can influence the interpretation of data [21,22]. Depending on the type of visualization used, identifying the key messages from the data visualization can be substantially hindered. The audience's background and its familiarity with data visualization (the visual domain context) have to be taken into account in the design process to avoid these obstacles. Example studies that identified the visual domain context by studying the design space can be found in the field of genomic epidemiology and genomic data visualization $[23,24]$. Although, some recommendations and best practices exist that are helpful in the data visualization creation process, common data visualizations practices in the field of stewardship have yet to be revealed $[25,26]$. The visual domain context and the use of data visualization in the field are unstudied - a systematic approach to define the design space is missing.

In this study, we aim to fill these gaps by assessing and defining the design space of data visualization in stewardship and to create a visual dictionary. The results of this study can help data visualization creators, such as healthcare/AMR/data professionals and scientists, to anticipate the visual domain context of the target audience and link it with existing recommendations for the data visualization process. This could benefit both research and clinical decision-making in the translation and communication of data to understandable and actionable information needed to tackle the AMR challenge, thereby improving the quality and safety of health and healthcare.

\section{Methods}

\section{Study data}

This study was based on a previous mapping study that clustered the field of AMR into 88 topics [27]. The map was generated by assessing the entire body of AMR literature available on PubMed between 1999 and 2018 consisting of 152780 articles. The identification of the 88 topics within the field was performed based on the title and abstract text using a machine learning algorithm (STM) [28]. The present study used all articles of three of the identified topics: stewardship ( $\mathrm{n}=3383$ articles), infection control ( $\mathrm{n}=1687$ articles), and institutional surveillance ( $n=2176$ articles). Within the corpus of the 88 topics, these three topics reflect the core components of an integrated, comprehensive stewardship concept in institutional healthcare as defined above [18]. 
For each topic, a sample of 60 articles that contained at least one data visualization was randomly drawn. Data visualization was defined as the graphical representation of quantitative data. Geographical maps and flowcharts were excluded. From the sampled articles, one visualization per article was randomly sampled resulting in 180 data visualizations. The study design is shown in Figure 2.

To analyse reliability, ten randomly picked data visualizations of each topic were analysed in duplicate to calculate the inter-rater reliability (joint probability of agreement) [29]. Subsequently, 150 visualizations were included in the final analysis.

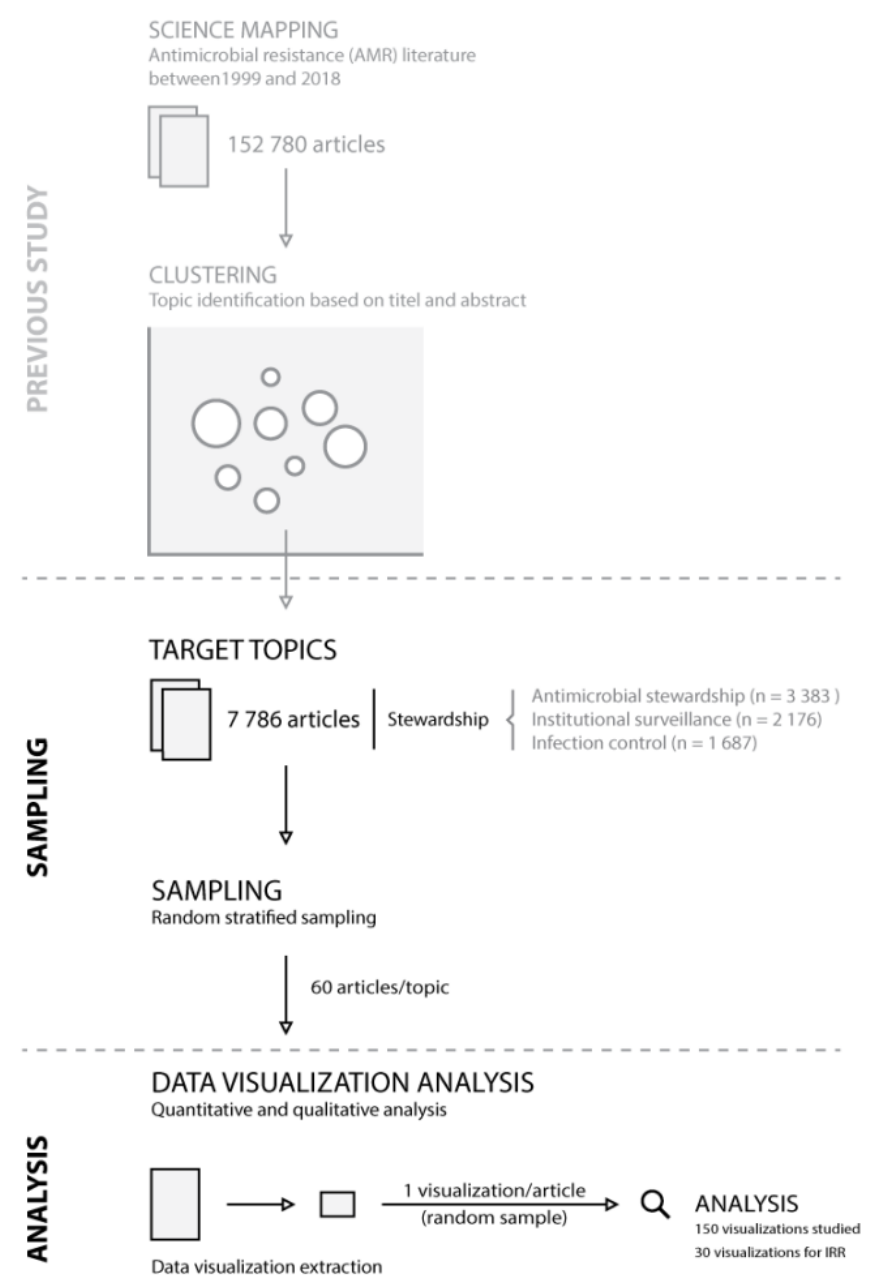

Figure 2. Study design. IRR = inter-rater reliability 


\section{Data visualization analysis}

The extracted data visualizations were analysed based on the nomenclature and categorization developed by Munzner and further adapted for this study [13]. This approach dissected data visualizations into visual characteristics:

- Attributes (or variables, parameters, features): the underlying data labelled as categorical, ordered, or quantitative.

- Marks: the basic geometric element (points, lines, or areas)

- Channel: channels control the visual appearance of marks

- Position: horizontal, vertical, both

- Colour

- Shape

- Tilt

- Size: length, area, volume

- Channel effectiveness

- Magnitude: ordered attributes can be expressed in ranks from most effective to least effective: position on common scale (most effective) > position on unaligned scale $>$ length $>$ tile/angle $>$ area $>$ depth $>$ colour luminance/saturation > curvature/volume (least effective)

- Identity: the effectiveness to express categorical attributes can also be ordered: colour hue > shape

In addition, data visualizations were labelled with the visualization type used (e.g., bar chart, line chart, scatter plot, etc.) and the use of faceting (multiple linked visualizations in a design grid). Each visualization was assessed upon its interpretability without additional text (yes, if interpretable without additional information; partially, if a description was given in a caption; not all, if a description was absent or only available in the article text).

Visualization quality was captured by rating the first and last impression during the analysis process on a scale form 1 (poor) to 5 (good). The choice of the visualization type given the underlying data was rated on a scale from 1 (poor) to 5 (good). In addition, free, written text was recorded to capture comments and remarks about the data visualization.

A structured assessment form (supplementary materials S1) was developed comprising all the above mentioned elements. 
The form was discussed within a multidisciplinary team of data-visualization and AMR experts. The assessment form was applied to each data visualization in a two reviewer (JK, CFL) process. First, the assessment form was used for training the analysis process with ten data visualizations not part of the final study data. Next, each reviewer analysed $50 \%$ of the study data visualizations followed by a re-review through the other researcher. Consensus was reached through discussion if the first assessment differed.

\section{Quantitative analysis}

Results from the data visualization analysis step that were analysed with descriptive statistics comprised visualization type, number of attributes, faceting, rating, and visualization type choice. Attributes were analysed for pairwise co-occurrence and presented if a combination occurred more than twice in total.

\section{Visual dictionary}

The visual dictionary was created based on the visual vocabulary content (stewardship-related data) and the visual design space (characteristics used to design the visualization). The content was analysed by identifying the attributes and grouping the attribute names using inductive coding. This part built the vocabulary of visualized stewardship data. Next, stratified quantitative analyses of visual characteristics (channel, marks, etc.) per attribute were performed, thereby adding the visual design space to the vocabulary to create the visual dictionary. Linking text and visual vocabulary enabled the creation of a visual dictionary to help identify attributes (e.g., resistance) with associated channels (e.g., points and lines on a common scale).

\section{Qualitative analysis}

Comments and remarks about the data visualizations were coded in Microsoft Excel by two researchers ( $\mathrm{CL}$ and $\mathrm{JK}$ ). An open coding round was followed by axial coding to discover related concepts in the sub-codes. Differences were discussed until consensus was reached, which increased the internal validity [30]. Next to improvements, CL and JK coded remarks about chart junk (i.e. the unnecessary and/or redundant use of visualization embellishments) [11]. 


\section{Results}

In total, 150 visualizations were analysed (IRR: $87 \%$ joint probability of agreement). The following sections are separated into visualization vocabulary (content) and visual dictionary with results stratified by identified attributes. These sections are followed by visualization ratings, identified visualization problems (including chart junk), and suggested recommendations for visualization creators and users.

\section{Visual vocabulary (content)}

In total, 48 different coded attributes were identified. The majority (54.7\%) of visualizations used three attributes. Two or four attributes were used in $18.0 \%$ and $20.7 \%$ of all visualizations, respectively. Few of the studied visualizations $(6.7 \%)$ used more than 4 attributes.

The ten most used attributes were time ( $n=69,46.0 \%)$, setting $(n=43,28.7 \%)$, antimicrobial consumption $(n=32,21.3 \%)$, resistance $(n=31,20.1 \%)$, antimicrobials $(n=27,18.0 \%)$, percentage $(n=26,17.3 \%)$, count $(n=24,16.0 \%)$, incidence $(n=24,16.0 \%)$, numeric value $(n=20,13.3 \%)$, and bacteria $(n=12,8.0 \%)$. Attributes can be grouped into objects (e.g. bacteria) and measurements (e.g. percentage). However, the following analysis focuses on attribute combinations and attributes are thus kept ungrouped.

Attributes showed different co-occurrence patterns (Figure 2). The ten most frequent combinations were time and antimicrobial consumption $(n=21)$, time and incidence $(n=18)$, antimicrobial consumption and antimicrobials $(n=12)$, antimicrobials and resistance $(n=12)$, time and resistance $(n=12)$, time and antimicrobials $(n=11)$, antimicrobial consumption and setting $(n=10)$, resistance and setting $(n=9)$, time and setting $(n=9)$, and percentage and setting $(\mathrm{n}=8)$. 


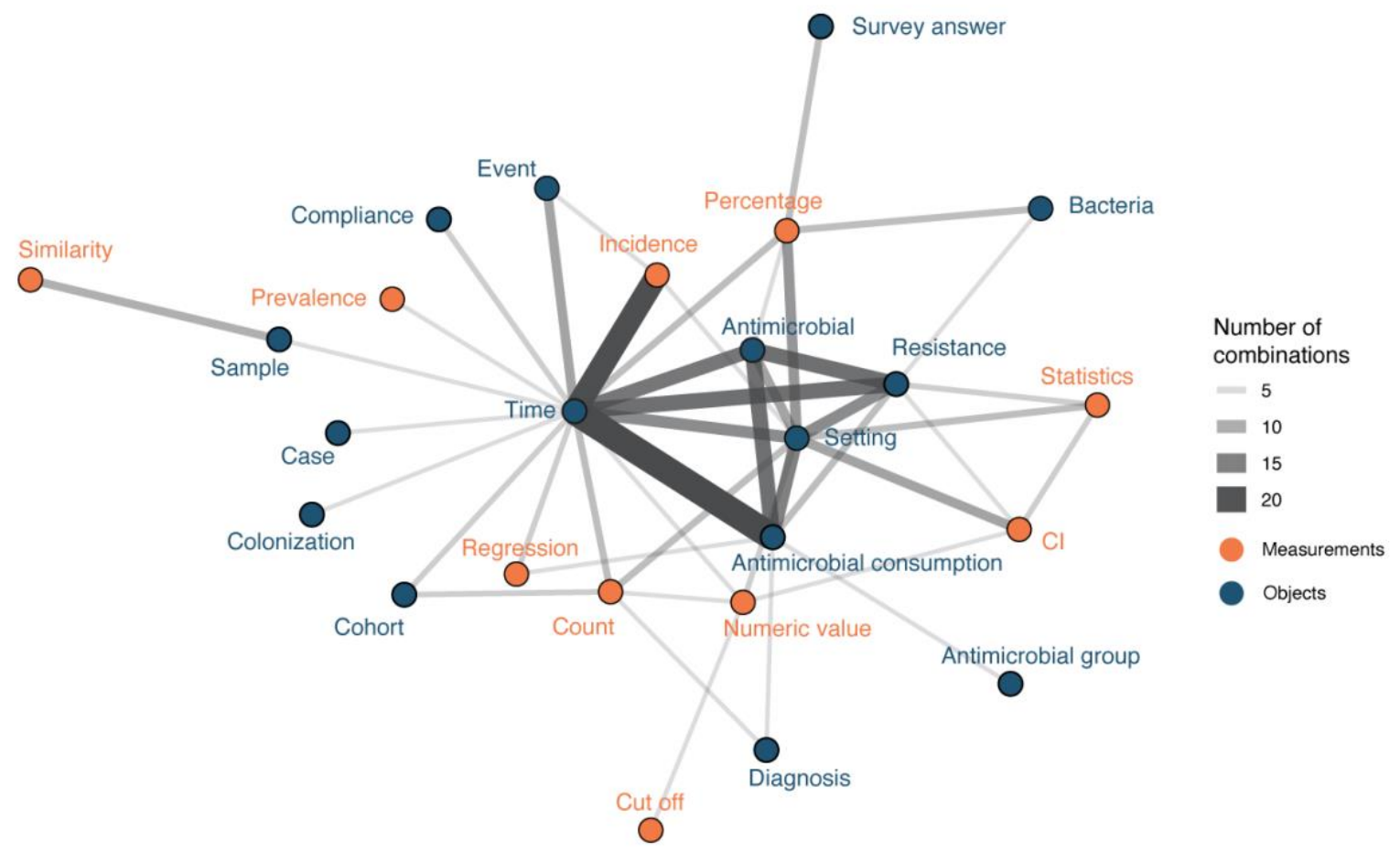

Figure 3. Attribute combinations in visualizations (combination count $\geq 3$ ), thickness of lines corresponds to combination count. Orange points and labels represent attributes related to measurements; blue points and labels represent attributes related to objects.

\section{Visual dictionary}

\section{Visualization types}

Fourteen different visualization types were identified of which bar charts $(n=54,36.0 \%)$ and line charts $(n=42,28.1 \%)$ were predominantly used. Bar charts were most frequently associated with the attributes antimicrobials, bacteria, cohorts, compliance, counts, diagnosis, errors, percentages, resistance, setting, and survey answers. Line charts were predominantly associated with antimicrobial consumption, costs, cut-off, incidence, numeric values, regression, statistics, and time (detailed results available in the supplementary materials S2)

Different visualization types combined in one visualization were used in $10.7 \%$ ( $n=16)$ of all visualizations. In these, visualization types that were combined more than once were bar charts with line charts $(n=5,31.3 \%)$ and stacked bar charts with line charts $(n=2,12.5 \%)$. In 41 visualization (27.3\%) facets were used, i.e., one visualization split into a matrix of visualizations using the same axes. 


\section{Visual design space}

Different patterns of visual characteristics could be identified for different attributes (detailed counts and percentages in supplementary materials S3).

1. Position: Horizontal axes were mostly used for Antimicrobials, bacteria, confidence intervals, counts, cut-offs, diagnoses, events, numeric values, settings, similarity, and time. In contrast, vertical axes were mostly used for antimicrobial consumption, cases, cohorts, counts, errors, incidence, percentages, regression, resistance, samples, statistics, and survey answers.

2. Marks, colour, shape: Attributes also differed in their use of marks. Some attributes had clear associations with mark types, e.g. time was visualised with lines in all instances. Areas as marks were seldomly used, e.g. for antimicrobial consumption, counts, cut-offs, incidence, numeric values, percentages, and resistance. Colour and shape channels were frequently used in most attributes. A detailed colour and shape channel analysis is available in the supplementary materials S3.

3. Size: Size was most often visually reflected through length. Area to reflect size was used for antimicrobial consumption, count, cut-off, incidence, numeric values, percentages, and resistance. Volume was rarely used (count, percentages).

4. Ordering: Position on a common scale was mostly used in quantitative and ordered attributes reflecting the best channel effectiveness for these attribute types. Categorical attributes mostly used colour hue, which is preferred over the less effective use of shapes. A detailed channel effectiveness analysis is available in the supplementary materials S4.

\section{Ratings, problems, and chart junk}

\section{Visualization ratings}

Overall, $55.3 \%$ ( $n=83$ ) of all visualizations were interpretable without additional text (in caption or in the manuscript text). The overall choice of visualization type for the presented data was rated with a mean of 4.62 (SD: 0.9 ) on a scale from 1 (poor) to 5 (good). The general assessment of the visualization quality (scale $1=$ poor to $5=\mathrm{good}$ ) was rated with a mean of 3.6 (SD:1.2). Identified problems (and recommendations) are described below.

\section{Identified problems}

The coding of the identified problems are presented in the coding scheme in Table 1, including 
bioRxiv preprint doi: https://doi org/10.1101/2021.05.19.444819; this version posted May 20,2021 . The copyright holder for this preprint (which was not certified by peer review) is the author/funder, who has granted bioRxiv a license to display the preprint in perpetuity. It is made available under aCC-BY 4.0 International license.

axial codes, open codes and frequencies. The axial and open codes are further elaborated upon below the table. In supplementary materials S5, additional illustrative quotes per code are presented.

Table 1. Identified problems in data visualization.

\begin{tabular}{|c|c|c|c|}
\hline Code (axial) & Code (open) & & Count \\
\hline \multirow{7}{*}{$\begin{array}{l}\text { Missing labels, annotations, } \\
\text { legend and/or abbreviation } \\
\text { explanations }\end{array}$} & Legend/caption is missing/unclear & & 26 \\
\hline & Labels for lines/points are missing/unclear & & 23 \\
\hline & Labels for axes are missing/unclear & & 20 \\
\hline & Annotation/direct labelling overflow & & 14 \\
\hline & Abbreviations not explained & & 12 \\
\hline & Use of colours not explained & & 7 \\
\hline & & Subtotal & 102 \\
\hline \multirow[t]{6}{*}{ Axes not readable } & $\begin{array}{l}\text { Axis intervals uneven (within visualization and between faceted } \\
\text { visualizations) }\end{array}$ & & 17 \\
\hline & Axes texts not clearly readable & & 11 \\
\hline & Too short/dense axes/intervals & & 5 \\
\hline & Uneven bar placement & & 1 \\
\hline & $\begin{array}{l}\text { Axis intervals not logical (within visualization and between faceted } \\
\text { visualizations) }\end{array}$ & & 1 \\
\hline & & Subtotal & 35 \\
\hline \multirow[t]{5}{*}{ Colour scheme mismatch } & Groups not distinguishable by colours & & 14 \\
\hline & Non-intuitive colour schemes used & & 6 \\
\hline & Categorical colours used for ordered attribute & & 5 \\
\hline & Groups not distinguishable from background & & 2 \\
\hline & & Subtotal & 27 \\
\hline \multirow{2}{*}{$\begin{array}{l}\text { Hidden data points by } \\
\text { overlaps }\end{array}$} & Overlap of shapes problematic & & 7 \\
\hline & & Subtotal & 7 \\
\hline \multirow{3}{*}{$\begin{array}{l}\text { Using suboptimal channel } \\
\text { effectiveness }\end{array}$} & Groups not distinguishable by shapes & & 12 \\
\hline & Sub-effective channel is chosen & & 3 \\
\hline & & Subtotal & 15 \\
\hline \multirow[t]{4}{*}{ Size scale indistinguishable } & Differences in size not clear & & 10 \\
\hline & Groups not distinguishable by shape size & & 3 \\
\hline & Contrasts between groups not clear & & 2 \\
\hline & & Subtotal & 15 \\
\hline \multirow[t]{3}{*}{ Missing channel } & Line types not used to distinguish between groups & & 2 \\
\hline & Colours not used to compare between visualization/groups & & 2 \\
\hline & & Subtotal & 4 \\
\hline $\begin{array}{l}\text { Visualization type does not } \\
\text { (optimally) fit data }\end{array}$ & Other visualization type preferred & & 21 \\
\hline
\end{tabular}

\begin{tabular}{|c|c|c|c|}
\hline & & Subtotal & 21 \\
\hline \multirow[t]{2}{*}{$\begin{array}{l}\text { Data points/lines on double } \\
\text { axes }\end{array}$} & Double Y-axes difficult to read & & 11 \\
\hline & & Subtotal & 11 \\
\hline \multirow[t]{5}{*}{ Channel overflow } & Double use of shape and colour & & 8 \\
\hline & Unnecessary use of shape sizes & & 1 \\
\hline & Unnecessary use of colour & & 1 \\
\hline & Too many colours & & 1 \\
\hline & & Subtotal & 11 \\
\hline \multirow[t]{3}{*}{ Attribute overflow } & Too many attributes & & 2 \\
\hline & Relating attributes that are not related & & 1 \\
\hline & & Subtotal & 3 \\
\hline
\end{tabular}




\begin{tabular}{|c|c|c|c|}
\hline \multirow{2}{*}{ Information sparsity } & \multirow[t]{2}{*}{ Could be text } & & 1 \\
\hline & & Subtotal & 1 \\
\hline \multirow[t]{3}{*}{ Incoherent ordering } & Data not ordered coherently & & 1 \\
\hline & & Subtotal & 1 \\
\hline & & Grand total & 253 \\
\hline
\end{tabular}

Most problems were related to the clarification of the visualization, because of missing or unclear labels, annotations, legend, captions and/or abbreviation explanations $(n=102$; $68.0 \%)$. Other problems concerned the axis readability $(n=35 ; 23.3 \%)$ for example due to uneven axis-intervals within a visualization and between faceted visualizations for comparison. Problems related to distinguishing data points and groups in visualizations were detected, for example with mismatches in colour scheme $(n=27 ; 18.0 \%)$, hidden data points by overlaps ( $n=7 ; 4.7 \%)$, and using suboptimal channel effectiveness ( $n=7,4.7 \%)$. In some cases, data points and groups were not clearly distinguishable because of the size scale $(n=15 ; 10.0 \%)$ or because of missing channels (e.g. line type or colour, $n=4 ; 2.7 \%$ ). Furthermore, problems identified were the suboptimal or wrong choice in type of visualization $(n=21 ; 14.0 \%)$ and the confusing use of double $y$-axis $(n=11 ; 7.3 \%)$. Some visualizations were overcrowded, either in terms of channel overflow (e.g. using both colour and shape, $n=11$; $7.3 \%$ ) or attribute overflow (e.g. too many attributes, $n=3 ; 2.0 \%$ ). On the contrary, the information in one visualization was sparse enough to be written in text (i.e. no added value of a visualization). Lastly, one problem related to the incoherent ordering of data.

\section{Chart junk}

Most chart junk represented text that cluttered the visualization $(n=8)$, for example with redundant direct labels for each data point. Other chart junk was found in visualizations using unnecessary 3D $(n=8)$, background colours $(n=6)$, shadow $(n=4)$, and colour/shape filling $(n=4)$.

\section{Examples and recommendations}

To illustrate problems in data visualization, we designed a visualization that exhibits several of the identified problems based on simulated data (Figure 4). Figure 5 proposes an alternative to Figure 4 where the identified problems were avoided. Of note, data such as the simulated data in these figures can be visualised in many different ways, depending on the underlying research questions. 
bioRxiv preprint doi: https //doi org/10.1101/2021.05.19.444819; this version posted May 20, 2021. The copyright holder for this preprint (which was not certified by peer review) is the author/funder, who has granted bioRxiv a license to display the preprint in perpetuity. It is made available under aCC-BY 4.0 International license.

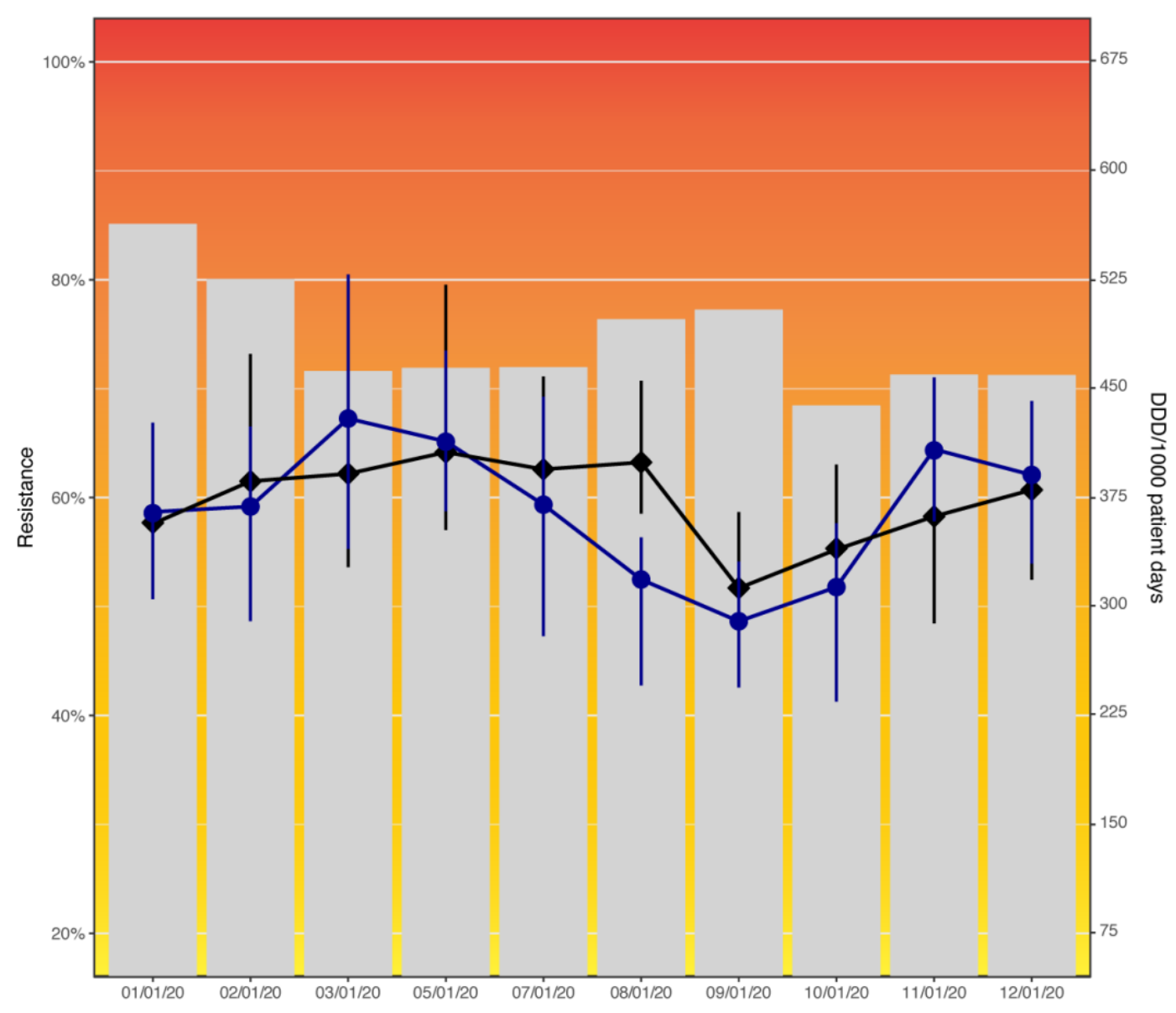

Figure 4. Resistance to amoxicillin in Escherichia coli and consumption of cefuroxime (black) and piperacillin/tazobactam (blue) across hospital departments in 2020. This data visualization (simulated data) shows several problems identified in this study: Axes not starting at zero, use of double y-axes, background colours, hidden data points by overlaps, colour scheme mismatch (blue and black difficult to distinguish), unequal axis steps on $\mathrm{x}$-axis, missing legend, incomplete axis labels (abbreviation not explained). 


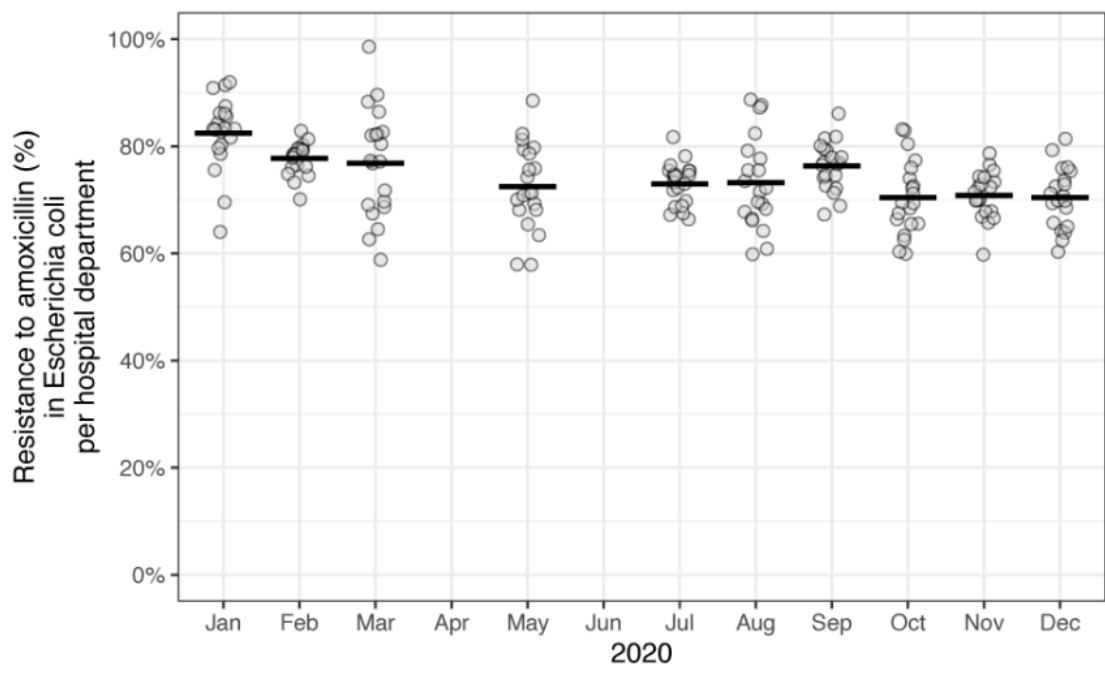

- Mean resistance (\%)

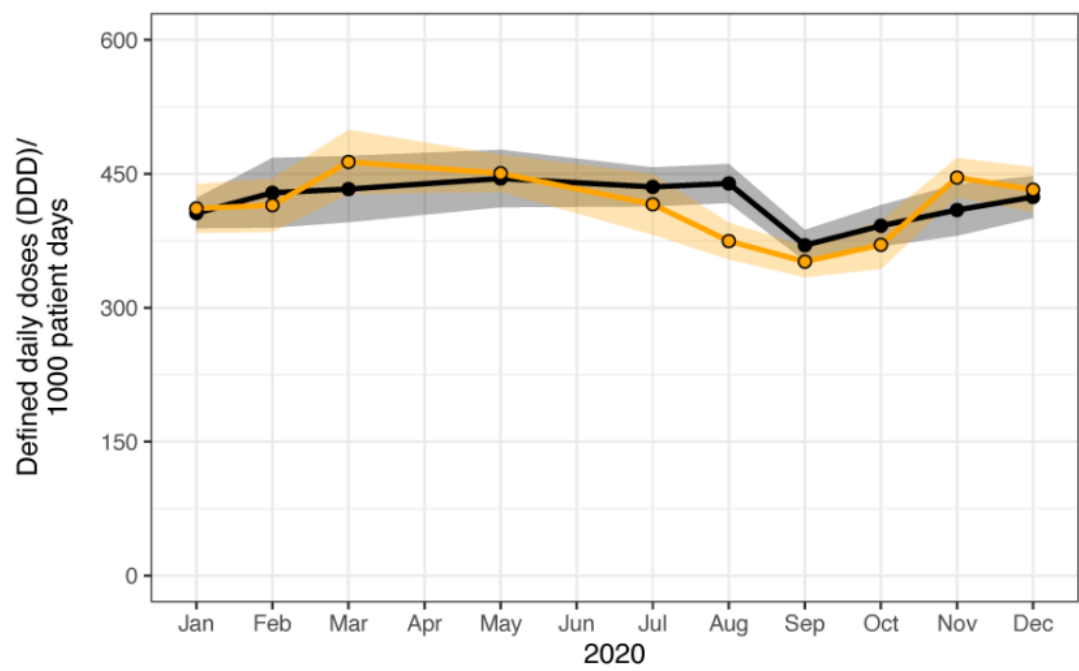

Mean DDD/1000 patient days

$\rightarrow$ Cefuroxime

-o- Piperacillin/tazobactam

Standard deviation DDD/1000 patient days

Cefuroxime

Piperacillin/tazobactam

Figure 5. Resistance to amoxicillin in Escherichia coli and consumption of cefuroxime and piperacillin/tazobactam across hospital departments in 2020 . These data visualizations use the same data as in Figure 4 (simulated data), but propose an improved visualization.

Figure 6 summarises the results of this study and presents the visual dictionary of stewardship. In addition, it provides a set of recommendations to avoid the most common problems in data visualizations as identified in this study. 
bioRxiv preprint doi: https://doi.org/10.1101/2021.05.19.444819; this version posted May 20, 2021. The copyright holder for this preprint (which was not certified by peer review) is the author/funder, who has granted bioRxiv a license to display the preprint in perpetuity. It is made available under aCC-BY 4.0 International license.

\section{The Visual Dictionary of Stewardship (Antimicrobial Stewardship, Infection Control, and Surveillance)}

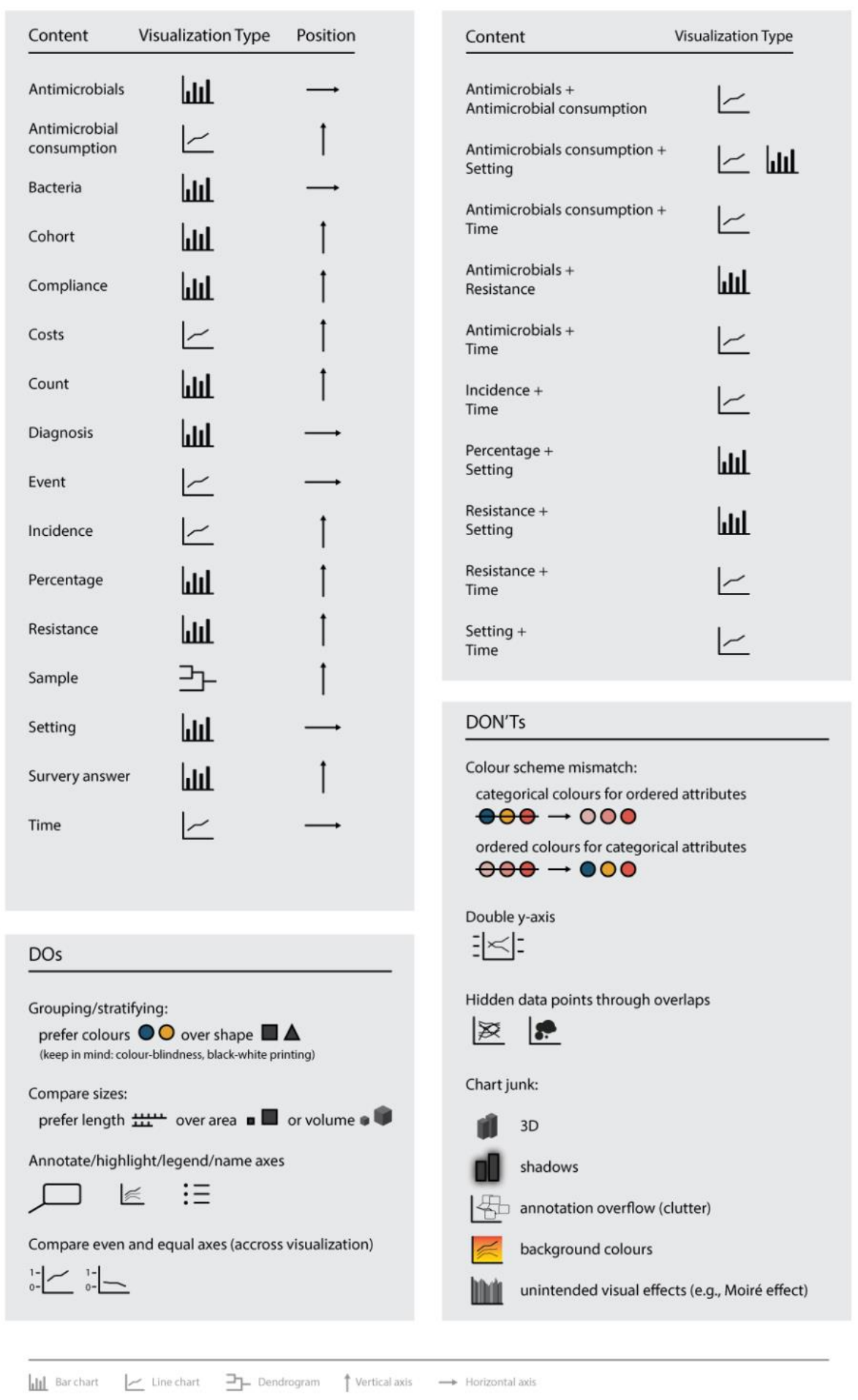

Figure 6. The visual dictionary of stewardship (antimicrobial stewardship, infection control, and institutional surveillance). 


\section{Discussion}

This study systematically analysed the visual domain context of stewardship (i.e. antimicrobial stewardship, infection control, and institutional surveillance). Stewardship healthcare experts and scientists that create data visualizations can benefit from the revealed visual domain context, since it allows them to anticipate the visual habits of their target audience. The results of this study can serve as the basis to inform visualization creators to optimise visual communication in the field and to guide user-centred design, e.g., in clinical decision support systems.

\section{Implications for data visualization creators}

With the systematic analysis of the visual domain context of Stewardship we revealed common practices and identified problems with current visualizations. In this study we identified 14 different visualization types used in the visual domain context of the field. However, more than $80 \%$ of all visualizations used classical (stacked) bar or line charts; quite homogenous design choices. We argue that the visualization type choice is based on tradition and habits as a systematic approach to data visualization in the field was missing until now [26]. For researchers in the field that communicate their findings to various stakeholders (e.g. stewardship professionals, policy makers, epidemiologists) the described visual domain context in this study provides guidance to match their visualizations with the audience's visual expectations and habits. Especially the visual dictionary, the link between often used attributes (i.e. content) and associated design choices (e.g. visualization type or marks), will help to compose visualizations that fit with common practice. However, given the wide variety of data in the field and the increased complexity that big data will add (in terms of volume, velocity, variety, veracity, validity, volatility and value), more "visual variability" might be expected and even needed in the future [3,31,32]. Informing and teaching visualization creators and users about data visualization design alternatives is an important step in this process. A lack of awareness and knowledge about data visualization design alternatives might lead to suboptimal data visualizations. Examples from our findings were the use of less effective visual channels, suboptimal plot types for the presented data, or mismatches in colour choices for different data types. These are examples of instances where the respective data visualization creators require more support in visualization design choices. We see a clear role here for data visualization experts and software developers to cocreate opensource/access tools that support visualization creators in their visualization choices (e.g. reminders for adding labels and legends, suggestions for optimal colour schemes, warnings in case of chart junk). Our results and findings from similar studies in other fields $[23,24]$ can 
support them in doing so by providing an overview of what is already used, including potential pitfalls. Of note, academic journals play an important part in this process by providing the platform for data visualizations and should be encouraged to promote high quality data visualization practices.

\section{Improving data visualization practices}

In general, the use of data visualizations for communicating data is highly encouraged. It greatly supports the interpretation, memorisation, and communication of insights and knowledge gained from data. Based on the identified problems with data visualizations in this study, several recommendations can be made to improve data visualization practices both in general and for stewardship specifically. Some recommendations relating to identified problems were already depicted in Figure 5 and 6 and are elaborated and extended upon below.

\section{Colours}

The use of colours in data visualization is highly complex. Colours can make a plot more appealing. Colours are also more effective than shape to distinguish categorical data [13]. Yet, shapes for categorical data were still widely used in the studied visualizations. This could reflect the need to provide visualizations that are black-and-white compatible (printable), although this has become less important with most of the scientific content being accessible online. Several aspects are key to consider when designing data visualizations with colour: colour-blindness, distortion through uneven colour gradients, or the perceived order of colours [33]. While field-specific colour codes might exist (e.g., red colour to represent resistance), general recommendations for the use of colours in scientific publications are available and are applicable across fields [33]. Extensive information on the use of colours in data visualization can also be found in online blogs from designers in the data visualization community (e.g., https://blog.datawrapper.de/which-colour-scale-to-use-in-data-vis/).

\section{Adding statistics}

Common scientific visualization types such as heatmaps or boxplots were rarely used in the studied data visualizations. In general, statistical aggregate parameters were often lacking. This would often have improved the visualizations under study. Boxplots are a classical example. However, this visualization type is rightfully criticised to conceal individual data points and could be misleading [34]. We also identified difficulties in displaying individual data points as one of the main problems. This problem was caused by overlaps, problematic scale 
sizes, or missing channels to distinguish data points. We highly advise to stick to the mantra of "above all show the data", to avoid overlapping or concealing graphical elements [11], and to carefully balance the number of visualised attributes per visualization with simplicity.

\section{Standardizing the visual dictionary}

Although a large variety of data were displayed in the studied visualizations (48 different attributes such as antimicrobials, bacteria, or time), we observed some prominent patterns in the content and purpose of data visualization. Changes over time, e.g. time series, were part of $43.3 \%$ of all studied visualization. Twenty percent and $19.3 \%$ included antimicrobial consumption or resistance, respectively. This is not surprising given the importance of these data in the field. It could be worth considering to standardise data visualizations for these data types and contents similar to the consensus of international guidelines committees in the field, e.g. the European Committee of Antimicrobial Susceptibility Testing (EUCAST) or the Clinical \& Laboratory Standards Institute (CLSI). This could help ensure high quality data visualizations for reliable insights in AMR- and stewardship-related data. Such initiatives to standardise data visualizations have already been taken by bodies in other fields, e.g. the Intergovernmental Panel on Climate Change (IPCC) [35]. Another example is the development and evaluation of a standardised medical data visualization method based on the ISO13606 data model [36].

\section{Limitations and strengths}

This study has several limitations. Despite sampling from a comprehensive set of articles that cover the field of stewardship (antimicrobial stewardship, infection control, and institutional surveillance), only a limited sample of data visualizations were included. Data visualizations for content (attributes) not covered in this study could have been missed. However, the homogeneity of the identified data visualization types suggests that saturation was reached regarding the visual design space in the field. Another limitation is that we included data visualizations from scientific publications and not from other sources relevant to stewardship data visualizers (e.g. data systems used in practice [12,37] and AMR policy reports [38,39]). As a result, our findings might be more applicable to stewardship researchers and data visualization experts than healthcare professionals. Another use of data visualization, namely the exploration of increasingly complex big data, was outside the scope of the included articles $[40,41]$. Subsequent research into the visual domain context of stewardship should include these additional data visualization sources and applications to ensure a more comprehensive picture for healthcare professionals. Even though the extracted data visualizations were 
systematically analysed using a structured assessment form based on existing data visualization nomenclature and categorization [13], the analyses relied on the subjective interpretation and rating by the coding researchers. Several measures were taken to validate our findings, including discussing the assessment form and results within a multidisciplinary team of data-visualization and AMR experts, analysing the interrater-reliability, and comparing our findings to other data visualization studies. Our study is one of the first empirical studies that explores the use of data visualization in stewardship, thereby adding to the few review studies providing primers for data visualization recommendations and best practices in the field of antimicrobial stewardship, infection control, and institutional surveillance $[25,26]$.

\section{Future perspectives}

Future research can build upon our results by studying and expanding the use and design of data visualizations beyond the basic visual dictionary provided here. Two important future research directions are elaborated upon below.

Studying the visual domain context is as important as studying data visualizations themselves. This includes studying expectations and customs of the target audience, how this affects their perception and interpretation of data visualizations, and how this consequently impacts their decision-making or behaviour. The importance of assessing visual habits and perceptions in data visualization has been demonstrated before in other medical fields $[21,42]$. It was shown that personal preferences and the familiarity of a target audience with certain visualization types can result in tensions with data visualization recommendations and novel data visualization approaches. An example is the use of pie charts, which is often discouraged in the data visualization community. The target audience might still favour this type of visualization because of its apparent simplicity, despite the fact that pie charts are less accurately interpreted as angles and wedges are difficult to compare $[8,43]$. We strongly believe that incorporating best practices and data visualization recommendations are essential but advocate that these should be carefully balanced with visual habits and expectations in the field, and the message to be transported. An exemplary study is published by Aung et al. focusing on data visualization interpretation capacity and preferences in their target audience by combining interviews on interpretability and card-sorting of preferred visualizations [21]. Additionally, research is needed to better understand how data visualizations impact the viewers/users in terms of changes in opinions or attitudes that direct decision-making or behaviour changes [44]. 
In future research special attention should be paid to matching the visual dictionary and the context in which the visualization will be used in terms of users and their tasks and current practices (e.g. studying questions like "What kinds of visualizations are currently used?" and "How do they support to do current tasks?") [45]. We see a clear parallel with user-centred eHealth design that emphasises the need of a holistic understanding of the interrelations between technology, people and their context [46]. Both qualitative (e.g. interviews) and quantitative (e.g. eye-tracking in current data visualizations) study designs can contribute to such a holistic understanding, which in turn can inform or improve the design of visualizations (or eHealth) in terms of required content, functionalities and usability [47]. Therefore, complementing research on data visualizations, as the current study and many other studies do, with research that primarily focuses on the interaction between people, their context and how data visualizations can support them, is needed [45].

\section{Conclusion}

In this study, we analysed the visual domain context of stewardship (antimicrobial stewardship, infection control, and institutional surveillance). We successfully created a visual dictionary that can support the process of creating and using tailor-made data visualizations in the field. Thereby, our results allow data visualization creators to learn the visual language of the diverse field of stewardship. As data-driven solutions for stewardship are of increasing importance, effective processes of transforming this data to insights and knowledge is essential. Data visualization supports and enables this transformation and our results can guide the optimal visualization design choices that are grounded on expectations and habits in the field. In the future, our study can provide the basis to further expand the visual dictionary of antimicrobial stewardship towards more effective data visualizations that improve data insights, knowledge, and decision-making. 


\section{Acknowledgement}

The authors would like to thank Anamaria Crisan, Tamara Munzner, and Nils Gehlenborg for the inspiration provided for this study.

\section{Funding}

This research was supported by the INTERREG-VA (202085) funded project EurHealth1Health (http://www.eurhealth1health.eu), part of a Dutch-German cross-border network supported by the European Commission, the Dutch Ministry of Health, Welfare and Sport, the Ministry of Economy, Innovation, Digitalisation and Energy of the German Federal State of North Rhine-Westphalia and the Ministry for National and European Affairs and Regional Development of Lower Saxony. In addition, this study was part of a project funded by the European Union's Horizon 2020 research and innovation programme under the Marie Sklodowska-Curie grant agreement 713660 (MSCA-COFUND-2015-DP "Pronkjewail").

\section{References}

[1] Murdoch TB, Detsky AS. The inevitable application of big data to health care. JAMA 2013;309:1351-2. https://doi.org/10.1001/jama.2013.393.

[2] Wang Y, Kung L, Byrd TA. Big data analytics: Understanding its capabilities and potential benefits for healthcare organizations. Technol Forecast Soc Change 2018;126:3-13. https://doi.org/10.1016/j.techfore.2015.12.019.

[3] Khan MA-U-D, Ali-ud-din Khan M, Uddin MF, Gupta N. Seven V's of big Data understanding big data to extract value. Proceedings of the 2014 Zone 1 Conference of the American Society for Engineering Education, Bridgeport, USA; 2014. https://doi.org/10.1109/aseezone1.2014.6820689.

[4] Ambigavathi M, Sridharan D. Big data analytics in healthcare. 2018 Tenth International Conference on Advanced Computing (ICoAC), Chennai, India; IEEE; 2018. https://doi.org/10.1109/icoac44903.2018.8939061.

[5] Adam Bohr KM. The rise of artificial intelligence in healthcare applications. Artificial Intelligence in Healthcare 2020:25. https://doi.org/10.1016/B978-0-12-818438-7.000022.

[6] Bailly S, Meyfroidt G, Timsit J-F. What's new in ICU in 2050: big data and machine learning. Intensive Care Med 2018;44:1524-7. https://doi.org/10.1007/s00134-0175034-3.

[7] Comba JLD. Data visualization for the understanding of COVID-19. Computing in Science Engineering 2020;22:81-6. https://doi.org/10.1109/MCSE.2020.3019834.

[8] Evergreen SDH. Effective data visualization: the right chart for the right data. Los Angeles: SAGE Publications; 2017.

[9] Gatto MAC. Making research useful: current challenges and good practices in data visualisation. Oxford: Reuters Institute for the Study of Journalism; 2015.

[10] Kelleher C, Wagener T. Ten guidelines for effective data visualization in scientific publications. Environmental Modelling \& Software $2011 ; 26: 822-7$. 
https://doi.org/10.1016/j.envsoft.2010.12.006.

[11] Tufte ER. The Visual display of quantitative information. Cheshire: Graphics Press; 2001.

[12] Sedrakyan G, Mannens E, Verbert K. Guiding the choice of learning dashboard visualizations: linking dashboard design and data visualization concepts. Journal of Computer Languages 2019;50:19-38. https://doi.org/10.1016/j.jvlc.2018.11.002.

[13] Munzner T. Visualization analysis and design. CRC Press; 2014.

[14] OECD. Stemming the superbug tide. OECD Health Policy Studies 2018:224. https://doi.org/10.1787/9789264307599-en.

[15] World Health Organization. Global antimicrobial resistance surveillance system (GLASS) report: early implementation 2020. Geneva: World Health Organization; 2020.

[16] World Health Organization. Global action plan on antimicrobial resistance. Geneva: World Health Organization; 2015.

[17] Dyar OJ, Huttner B, Schouten J, Pulcini C, ESGAP (ESCMID Study Group for Antimicrobial stewardshiP). What is antimicrobial stewardship? Clin Microbiol Infect 2017;23:793-8. https://doi.org/10.1016/j.cmi.2017.08.026.

[18] Dik J-WH, Poelman R, Friedrich AW, Panday PN, Lo-Ten-Foe JR, van Assen S, et al. An integrated stewardship model: antimicrobial, infection prevention and diagnostic (AID). Future Microbiol 2016;11:93-102. https://doi.org/10.2217/fmb.15.99.

[19] Luz CF, Berends MS, Dik J-WH, Lokate M, Pulcini C, Glasner C, et al. Rapid analysis of diagnostic and antimicrobial patterns in $R($ RadaR): interactive open-source software app for infection management and antimicrobial stewardship. J Med Internet Res 2019;21:e12843. https://doi.org/10.2196/12843.

[20] Graber CJ, Jones MM, Goetz MB, Madaras-Kelly K, Zhang Y, Butler JM, et al. Decreases in antimicrobial use associated with multihospital implementation of electronic antimicrobial stewardship tools. Clin Infect Dis 2020;71:1168-76. https://doi.org/10.1093/cid/ciz941.

[21] Aung T, Niyeha D, Shagihilu S, Mpembeni R, Kaganda J, Sheffel A, et al. Optimizing data visualization for reproductive, maternal, newborn, child health, and nutrition (RMNCH\&N) policymaking: data visualization preferences and interpretation capacity among decision-makers in Tanzania. Glob Health Res Policy 2019;4:4. https://doi.org/10.1186/s41256-019-0095-1.

[22] Aung T, Niyeha D, Heidkamp R. Leveraging data visualization to improve the use of data for global health decision-making. J Glob Health 2019;9:020319. https://doi.org/10.7189/jogh.09.020319.

[23] Crisan A, Gardy JL, Munzner T. A systematic method for surveying data visualizations and a resulting genomic epidemiology visualization typology: GEViT. Bioinformatics 2019;35:1668-76. https://doi.org/10.1093/bioinformatics/bty832.

[24] Nusrat S, Harbig T, Gehlenborg N. Tasks, techniques, and tools for genomic data visualization. Comput Graph Forum 2019;38:781-805. https://doi.org/10.1111/cgf.13727.

[25] Carroll LN, Au AP, Detwiler LT, Fu T-C, Painter IS, Abernethy NF. Visualization and analytics tools for infectious disease epidemiology: a systematic review. J Biomed Inform 2014;51:287-98. https://doi.org/10.1016/j.jbi.2014.04.006.

[26] Salinas JL, Kritzman J, Kobayashi T, Edmond MB, Ince D, Diekema DJ. A primer on data visualization in infection prevention and antimicrobial stewardship. Infect Control Hosp Epidemiol 2020;41:948-57. https://doi.org/10.1017/ice.2020.142.

[27] Luz CF, van Niekerk JM, Keizer J, Beerlage-de Jong N, Braakman-Jansen LMA, Stein A, et al. Mapping twenty years of antimicrobial resistance research trends. Cold Spring Harbor Laboratory 2021:2021.03.01.433375. https://doi.org/10.1101/2021.03.01.433375.

[28] Roberts ME, Stewart BM, Tingley D. stm: An R package for structural topic models. Journal of Statistical Software, Articles 2019;91:1-40. https://doi.org/10.18637/jss.v091.i02.

[29] O'Connor C, Joffe H. Intercoder reliability in qualitative research: Debates and practical 
guidelines. Int J Qual Methods 2020;19:160940691989922.

https://doi.org/10.1177/1609406919899220.

[30] Patton MQ. Enhancing the quality and credibility of qualitative analysis. Health Serv Res 1999;34:1189-208.

[31] Galletta A, Carnevale L, Bramanti A, Fazio M. An innovative methodology for big data visualization for telemedicine. IEEE Trans Ind Inf 2019;15:490-7. https://doi.org/10.1109/TII.2018.2842234.

[32] Gotz D, Borland D. Data-driven healthcare: challenges and opportunities for interactive visualization. IEEE Comput Graph Appl 2016;36:90-6. https://doi.org/10.1109/MCG.2016.59.

[33] Crameri F, Shephard GE, Heron PJ. The misuse of colour in science communication. Nat Commun 2020;11:5444. https://doi.org/10.1038/s41467-020-19160-7.

[34] Weissgerber TL, Winham SJ, Heinzen EP, Milin-Lazovic JS, Garcia-Valencia O, Bukumiric Z, et al. Reveal, don't conceal: transforming data visualization to improve transparency. Circulation 2019;140:1506-18. https://doi.org/10.1161/CIRCULATIONAHA.118.037777.

[35] Gomis MI, Pidcock R. IPCC visual style guide for authors. Stockholm: Intergovernmental Panel on Climate Change; 2018.

[36] Kopanitsa G, Veseli H, Yampolsky V. Development, implementation and evaluation of an information model for archetype based user responsive medical data visualization. Journal of Biomedical Informatics 2015;55:196-205. https://doi.org/10.1016/j.jbi.2015.04.009.

[37] Huber TC, Krishnaraj A, Monaghan D, Gaskin CM. Developing an interactive data visualization tool to assess the impact of decision support on clinical operations. J Digit Imaging 2018;31:640-5. https://doi.org/10.1007/s10278-018-0065-z.

[38] Anderson M, Clift C, Schulze K, Sagan A, Nahrgang S, Ait Ouakrim D, et al. Averting the AMR crisis: what are the avenues for policy action for countries in Europe? Copenhagen: European Observatory on Health Systems and Policies; 2019.

[39] World Health Organization. Central Asian and European Surveillance of Antimicrobial Resistance. Geneva: World Health Organization; 2020.

[40] Fisher D. Big data exploration requires collaboration between visualization and data infrastructures. Proceedings of the Workshop on Human-In-the-Loop Data Analytics, New York, NY, USA; Association for Computing Machinery; 2016,1-5. https://doi.org/10.1145/2939502.2939518.

[41] Kaysi B, Kesler EK. Human Computer Interaction and Visualization Tools in Health Care Services. In: Arabnia HR, Hashemi RR, G. TF, editors. Proceedings of the International Conference on Information and Knowledge Engineering (IKE), Athens, Greece; CSREA Press 2018;55-61.

[42] Backonja U, Haynes SC, Kim KK. Data visualizations to support health practitioners' provision of personalized care for patients with cancer and multiple chronic conditions: user-centered design study. JMIR Hum Factors 2018;5:e11826. https://doi.org/10.2196/11826.

[43] Cleveland WS, McGill R. Graphical perception: Theory, experimentation, and application to the development of graphical methods. J Am Stat Assoc 1984;79:531. https://doi.org/10.2307/2288400.

[44] Pandey AV, Manivannan A, Nov O, Satterthwaite M, Bertini E. The persuasive power of data visualization. IEEE Trans Vis Comput Graph 2014;20:2211-20. https://doi.org/10.1109/TVCG.2014.2346419.

[45] Lam H, Bertini E, Isenberg P, Plaisant C, Carpendale S. Empirical studies in information visualization: seven scenarios. IEEE Trans Vis Comput Graph 2012;18:1520-36. https://doi.org/10.1109/TVCG.2011.279.

[46] van Gemert-Pijnen L, Kelders SM, Kip H, Sanderman R. eHealth research, theory and development: a multi-disciplinary approach. Abingdon: Routledge; 2018.

[47] Keizer J, Beerlage-De Jong N, Al Naiemi N, van Gemert-Pijnen JEWC. Finding the match between healthcare worker and expert for optimal audit and feedback on 


\section{Supplementary materials}

\section{S1. Data Visualization Assessment Form}

\section{Assessor}

- Assessor 1

Assessor 2

Data visualization ID

₹ ID1 ... ID180

Year article

First impression
0 1: poor
$\circ 2$
$\circ 3$
○ 4
5: good

Viz type:
Violin
Density plot
Boxplot
Histogram
Scatter plot
Connected scatter plot
Bubble plot
Area plot 
bioRxiv preprint doi: https://doi org/10.1101/2021.05.19.444819; this version posted May 20, 2021. The copyright holder for this preprint (which was not certified by peer review) is the author/funder, who has granted bioRxiv a license to display the preprint in perpetuity. It is made available under aCC-BY 4.0 International license.

Stacked area plot

Stream plot

Line chart

Ridge line

Correlogram

Heatmap

Dendrogram

Bar chart

Stacked bar chart

Lollipop chart

Doughnut chart

Treemap

Circular packaging plot

Venn diagram

Sunburst diagram

Spider plot

Sankey diagram

Network plot

Chord diagram

Arc diagram

Hive plot

Hierarchical edge bundling

Other

Combined

Faceting (multiple groups in a grid)

- Yes

o No

Actions

Analyze

Search

Query - Identify

Query - Compare

Query - Summarize

Attributes 
bioRxiv preprint doi: https://doi.org/10.1101/2021.05.19.444819; this version posted May 20, 2021. The copyright holder for this preprint (which was not certified by peer review) is the author/funder, who has granted bioRxiv a license to display the preprint in perpetuity. It is made available under aCC-BY 4.0 International license.
01
○ 2
○ 3
- 4
- 5
- 6

Attribute names and types

\begin{tabular}{|c|c|c|c|c|c|c|}
\hline & \multirow{2}{*}{$\begin{array}{c}\text { Attribute } \\
\text { name }\end{array}$} & \multicolumn{5}{|c|}{ Attribute type } \\
\hline & & Categorical & Ordinal & Quantitative & NA & Mismatch \\
\hline Attr. 1 & & $\square$ & $\square$ & $\square$ & $\square$ & $\square$ \\
\hline Attr. 2 & & $\square$ & $\square$ & $\square$ & $\square$ & $\square$ \\
\hline Attr. 3 & & $\square$ & $\square$ & $\square$ & $\square$ & $\square$ \\
\hline Attr. 4 & & $\square$ & $\square$ & $\square$ & $\square$ & $\square$ \\
\hline Attr. 5 & & $\square$ & $\square$ & $\square$ & $\square$ & $\square$ \\
\hline Attr. 6 & & $\square$ & $\square$ & $\square$ & $\square$ & $\square$ \\
\hline
\end{tabular}


bioRxiv preprint doi: https://doi.org/10.1101/2021.05.19.444819; this version posted May 20, 2021. The copyright holder for this preprint (which was not certified by peer review) is the author/funder, who has granted bioRxiv a license to display the preprint in perpetuity. It is made available under aCC-BY 4.0 International license.

\begin{tabular}{l|lll} 
Points & Lines & Areas
\end{tabular}

Attr. 1

Attr. 2

Attr. 4

Attr. 5

Attr. 6

\section{Channels / position}

Horizontal

Vertical

Both

NA

Mismatch

Attr. 1

Attr. 2

Attr. 3 
bioRxiv preprint doi: https://doi.org/10.1101/2021.05.19.444819; this version posted May 20, 2021. The copyright holder for this preprint (which was not certified by peer review) is the author/funder, who has granted bioRxiv a license to display the preprint in perpetuity. It is made available under aCC-BY 4.0 International license.

Attr. 4

Attr. 5

Attr. 6

Channels / colour - shape - tilt

Color

Shape

Tilt

NA

Mismatch

Attr. 1

Attr. 2

Attr. 3

Attr. 4

Attr. 5

Attr. 6 
bioRxiv preprint doi: https://doi.org/10.1101/2021.05.19.444819; this version posted May 20, 2021. The copyright holder for this preprint (which was not certified by peer review) is the author/funder, who has granted bioRxiv a license to display the preprint in perpetuity. It is made available under aCC-BY 4.0 International license.

Channels / size

Length $\quad$ Area Nolume Nismatch

Attr. 1

Attr. 2

Attr. 3

Attr. 4

Attr. 5

Attr. 6

Channels effectiveness for ordered attributes :

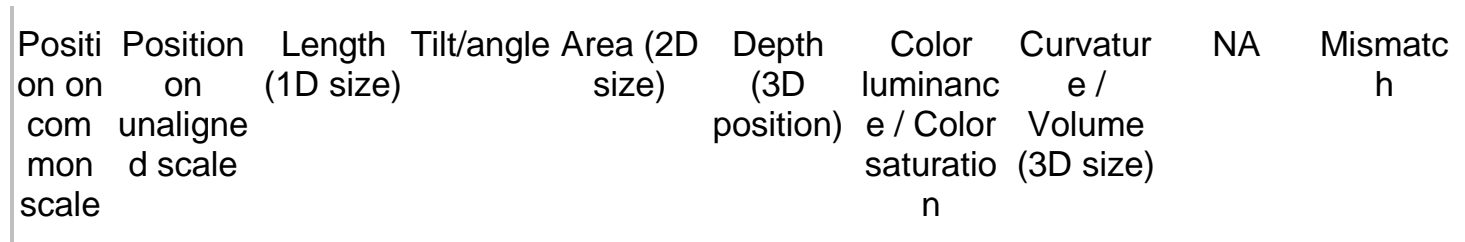

Attr. 1 
bioRxiv preprint doi: https://doi.org/10.1101/2021.05.19.444819; this version posted May 20, 2021. The copyright holder for this preprint (which was not certified by peer review) is the author/funder, who has granted bioRxiv a license to display the preprint in perpetuity. It is made available under aCC-BY 4.0 International license.

Attr. 2

Attr. 3

Attr. 4

Attr. 5

Attr. 6

Channels effectiveness for categorical attributes:

Spatial

Color hue

Motion

Shape

NA

Mismatch

position

Attr. 1

Attr. 2

Attr. 3 
bioRxiv preprint doi: https://doi. org/10.1101/2021.05.19.444819; this version posted May 20, 2021. The copyright holder for this preprint (which was not certified by peer review) is the author/funder, who has granted bioRxiv a license to display the preprint in perpetuity. It is made available under aCC-BY 4.0 International license.

Attr. 4

Attr. 5

Attr. 6

Describe what is visualized:

Interpretability without text
- 1 Not at all
- 2 Partially
$\circ$ Yes

Choice of plot type
1: poor
○ 2
○ 3
$\circ 4$
5: good

What can be improved?

Remarks (e.g. chart junk) 
bioRxiv preprint doi: https://doi.org/10.1101/2021.05.19.444819; this version posted May 20, 2021. The copyright holder for this preprint

\section{Last impression}
1: poor
02
○ 3
- 4
5: good

\section{S2. Visualization types per attribute}

Table S2

\begin{tabular}{|c|c|c|c|c|c|c|c|c|c|c|c|c|c|c|}
\hline Attribute & Line chart & $\begin{array}{c}\text { Bar } \\
\text { chart }\end{array}$ & $\begin{array}{l}\text { Stacked bar } \\
\text { chart }\end{array}$ & Dendrogram & $\begin{array}{l}\text { Forest } \\
\text { plot }\end{array}$ & $\begin{array}{c}\text { Range } \\
\text { plot }\end{array}$ & $\begin{array}{c}\text { Bubble } \\
\text { plot }\end{array}$ & $\begin{array}{c}\text { Pie } \\
\text { chart }\end{array}$ & $\begin{array}{c}\text { Tornado } \\
\text { plot }\end{array}$ & $\begin{array}{c}\text { Scatter } \\
\text { plot }\end{array}$ & $\begin{array}{c}\text { Bma } \\
\text { image plot }\end{array}$ & Heatmap & $\begin{array}{c}\text { Stacked } \\
\text { area plot }\end{array}$ & Correlogram \\
\hline Antimicrobial & $31.03 \%$ & $34.48 \%$ & $24.14 \%$ & & & & & $6.90 \%$ & & & $3.45 \%$ & & & \\
\hline $\begin{array}{l}\text { Antimicrobial } \\
\text { consumption }\end{array}$ & $46.15 \%$ & $23.08 \%$ & $25.64 \%$ & & & & & $2.56 \%$ & & $2.56 \%$ & & & & \\
\hline Bacteria & $8.33 \%$ & $58.33 \%$ & $8.33 \%$ & & & & $8.33 \%$ & & & & & $8.33 \%$ & $8.33 \%$ & \\
\hline Case & & & $16.67 \%$ & $16.67 \%$ & & $66.67 \%$ & & & & & & & & \\
\hline Confidence Interval & $18.18 \%$ & $27.27 \%$ & & & $45.45 \%$ & & & & & $9.09 \%$ & & & & \\
\hline Cohort & $20.00 \%$ & $40.00 \%$ & $20.00 \%$ & & & $20.00 \%$ & & & & & & & & \\
\hline Compliance & $11.11 \%$ & $77.78 \%$ & $11.11 \%$ & & & & & & & & & & & \\
\hline Cost & $40.00 \%$ & & & & & & & & $40.00 \%$ & $20.00 \%$ & & & & \\
\hline Count & $14.81 \%$ & $33.33 \%$ & $18.52 \%$ & & $3.70 \%$ & $7.41 \%$ & $14.81 \%$ & & & $7.41 \%$ & & & & \\
\hline Cut-off & $30.77 \%$ & $15.38 \%$ & & $15.38 \%$ & $15.38 \%$ & & $7.69 \%$ & & $7.69 \%$ & $7.69 \%$ & & & & \\
\hline Diagnosis & & $44.44 \%$ & $33.33 \%$ & & & & $11.11 \%$ & $\begin{array}{r}11.11 \\
\%\end{array}$ & & & & & & \\
\hline Error & & $80.00 \%$ & & & & $20.00 \%$ & & & & & & & & \\
\hline Event & $25.00 \%$ & $25.00 \%$ & $25.00 \%$ & & $8.33 \%$ & $16.67 \%$ & & & & & & & & \\
\hline Incidence & $37.04 \%$ & $22.22 \%$ & $22.22 \%$ & & $3.70 \%$ & $7.41 \%$ & & & & $3.70 \%$ & & & $3.70 \%$ & \\
\hline Numeric value & $47.83 \%$ & $26.09 \%$ & & & $13.04 \%$ & $4.35 \%$ & & & & $4.35 \%$ & $4.35 \%$ & & & \\
\hline
\end{tabular}


bioRxiv preprint doi: https://doi.org/10.1101/2021.05.19.444819; this version posted May 20, 2021. The copyright holder for this preprint (which was not certified by peer review) is the author/funder, who has granted bioRxiv a license to display the preprint in perpetuity. It is made available under aCC-BY 4.0 International license.

\begin{tabular}{|c|c|c|c|c|c|c|c|c|c|c|c|}
\hline Percentage & $7.41 \%$ & $51.85 \%$ & $22.22 \%$ & & $3.70 \%$ & & $\begin{array}{r}11.11 \\
\%\end{array}$ & & $3.70 \%$ & & \\
\hline Regression & $62.50 \%$ & & & & & & $12.50 \%$ & $25.00 \%$ & & & \\
\hline Resistance & $35.14 \%$ & $40.54 \%$ & $10.81 \%$ & & $2.70 \%$ & & $5.41 \%$ & $5.41 \%$ & & & \\
\hline Sample & & $8.33 \%$ & $8.33 \%$ & $50.00 \%$ & & $16.67 \%$ & & & $8.33 \%$ & & $8.33 \%$ \\
\hline Setting & $15.22 \%$ & $41.30 \%$ & $19.57 \%$ & $2.17 \%$ & $8.70 \%$ & $4.35 \%$ & $2.17 \%$ & $4.35 \%$ & $2.17 \%$ & & \\
\hline Similarity & & & & $80.00 \%$ & & & & & $10.00 \%$ & & $10.00 \%$ \\
\hline Statistics & $33.33 \%$ & $33.33 \%$ & & & $16.67 \%$ & & & $8.33 \%$ & $8.33 \%$ & & \\
\hline Survey answer & & $50.00 \%$ & $37.50 \%$ & & & & $12.50 \%$ & & & & \\
\hline Time & $52.63 \%$ & $25.00 \%$ & $10.53 \%$ & & & $6.58 \%$ & $2.63 \%$ & $1.32 \%$ & & $1.32 \%$ & \\
\hline
\end{tabular}

\section{S3. Visual characteristics per attribute}

\begin{tabular}{|c|c|c|c|c|c|c|c|c|c|c|c|c|}
\hline \multirow[b]{2}{*}{ Attribute } & \multicolumn{3}{|c|}{ Channel - position } & \multicolumn{3}{|c|}{ Channel - marks } & \multicolumn{3}{|c|}{ Channel - colour/shape/tilt } & \multicolumn{3}{|c|}{ Channel - size } \\
\hline & Horizontal & Vertical & Both & Areas & Lines & Points & Color & Shape & Tilt & Area & Length & Volume \\
\hline Antimicrobial & $72.73 \%$ & $27.27 \%$ & & & & & $64.71 \%$ & $35.29 \%$ & & & & \\
\hline Antimicrobial consumption & $3.13 \%$ & $96.88 \%$ & & $3.03 \%$ & $48.48 \%$ & $48.48 \%$ & $33.33 \%$ & $66.67 \%$ & & $6.25 \%$ & $93.75 \%$ & \\
\hline Bacteria & $71.43 \%$ & $14.29 \%$ & $14.29 \%$ & & & & $80.00 \%$ & $20.00 \%$ & & & & \\
\hline Case & $20.00 \%$ & $80.00 \%$ & & & & & & & & & & \\
\hline Confidence interval & $60.00 \%$ & $30.00 \%$ & $10.00 \%$ & & $81.82 \%$ & $18.18 \%$ & & $100.00 \%$ & & & $100.00 \%$ & \\
\hline Cohort & $40.00 \%$ & $60.00 \%$ & & & & $100.00 \%$ & $75.00 \%$ & $25.00 \%$ & & & & \\
\hline Compliance & & $100.00 \%$ & & & $83.33 \%$ & $16.67 \%$ & $100.00 \%$ & & & & $100.00 \%$ & \\
\hline Cost & $40.00 \%$ & $60.00 \%$ & & & $50.00 \%$ & $50.00 \%$ & & & & & $100.00 \%$ & \\
\hline Count & $23.81 \%$ & $76.19 \%$ & & $5.26 \%$ & $63.16 \%$ & $31.58 \%$ & $100.00 \%$ & & & $18.75 \%$ & $75.00 \%$ & $6.25 \%$ \\
\hline Cut-off & $66.67 \%$ & $11.11 \%$ & $22.22 \%$ & $12.50 \%$ & $75.00 \%$ & $12.50 \%$ & $100.00 \%$ & & & $50.00 \%$ & $50.00 \%$ & \\
\hline Diagnosis & $80.00 \%$ & $20.00 \%$ & & & & & $75.00 \%$ & $25.00 \%$ & & & & \\
\hline Error & $40.00 \%$ & $60.00 \%$ & & & $100.00 \%$ & & $100.00 \%$ & & & & $100.00 \%$ & \\
\hline Event & $100.00 \%$ & & & & $33.33 \%$ & $66.67 \%$ & $25.00 \%$ & $75.00 \%$ & & & $100.00 \%$ & \\
\hline Incidence & $8.70 \%$ & $91.30 \%$ & & $5.00 \%$ & $45.00 \%$ & $50.00 \%$ & $28.57 \%$ & $71.43 \%$ & & $9.09 \%$ & $90.91 \%$ & \\
\hline Numeric value & $55.00 \%$ & $40.00 \%$ & $5.00 \%$ & $6.67 \%$ & $40.00 \%$ & $53.33 \%$ & & & & $33.33 \%$ & $66.67 \%$ & \\
\hline Percentage & $34.78 \%$ & $60.87 \%$ & $4.35 \%$ & $12.50 \%$ & $75.00 \%$ & $12.50 \%$ & $66.67 \%$ & $33.33 \%$ & & $8.70 \%$ & $78.26 \%$ & $13.04 \%$ \\
\hline Regression & & $71.43 \%$ & $28.57 \%$ & & $71.43 \%$ & $28.57 \%$ & $33.33 \%$ & $66.67 \%$ & & & & \\
\hline Resistance & $7.41 \%$ & $92.59 \%$ & & $3.70 \%$ & $51.85 \%$ & $44.44 \%$ & $77.78 \%$ & $22.22 \%$ & & $7.14 \%$ & $92.86 \%$ & \\
\hline Sample & & $100.00 \%$ & & & & & $100.00 \%$ & & & & & \\
\hline Setting & $60.87 \%$ & $39.13 \%$ & & & $33.33 \%$ & $66.67 \%$ & $59.38 \%$ & $40.63 \%$ & & & & \\
\hline Similarity & $100.00 \%$ & & & & $100.00 \%$ & & & & & & $100.00 \%$ & \\
\hline Statistics & $22.22 \%$ & $77.78 \%$ & & & $50.00 \%$ & $50.00 \%$ & $66.67 \%$ & $33.33 \%$ & & & $100.00 \%$ & \\
\hline Survey answer & $40.00 \%$ & $60.00 \%$ & & & & $100.00 \%$ & $75.00 \%$ & $25.00 \%$ & & & & \\
\hline Time & $100.00 \%$ & & & & $100.00 \%$ & & $55.56 \%$ & $33.33 \%$ & $11.11 \%$ & & $100.00 \%$ & \\
\hline
\end{tabular}




\section{S4. Channel effectiveness for quantitative, ordinal and categorical attributes}

\begin{tabular}{lrrr}
\multicolumn{1}{c}{ Eable S4 } & & & \\
\hline \multicolumn{1}{c}{ Effectiveness } & Quantitative & Ordinal & Categorical \\
\hline Position on common scale & $82.8 \%$ & $83.0 \%$ & \\
Position on unaligned scale & $1.1 \%$ & $1.0 \%$ & \\
Length (1D size) & $3.4 \%$ & $2.0 \%$ & \\
Area (2D size) & $6.7 \%$ & $2.0 \%$ & \\
Depth (3D position) & $0.4 \%$ & & $1.3 \%$ \\
Color luminance/ & $5.6 \%$ & $12.0 \%$ & $68.9 \%$ \\
Color saturation & & & $29.8 \%$ \\
Spatial position & & & \\
Color hue & & & \\
Shape & & & \\
\hline
\end{tabular}

\section{S5. Problems and illustrative quotes.}

Table S5. Problems and illustrative quotes

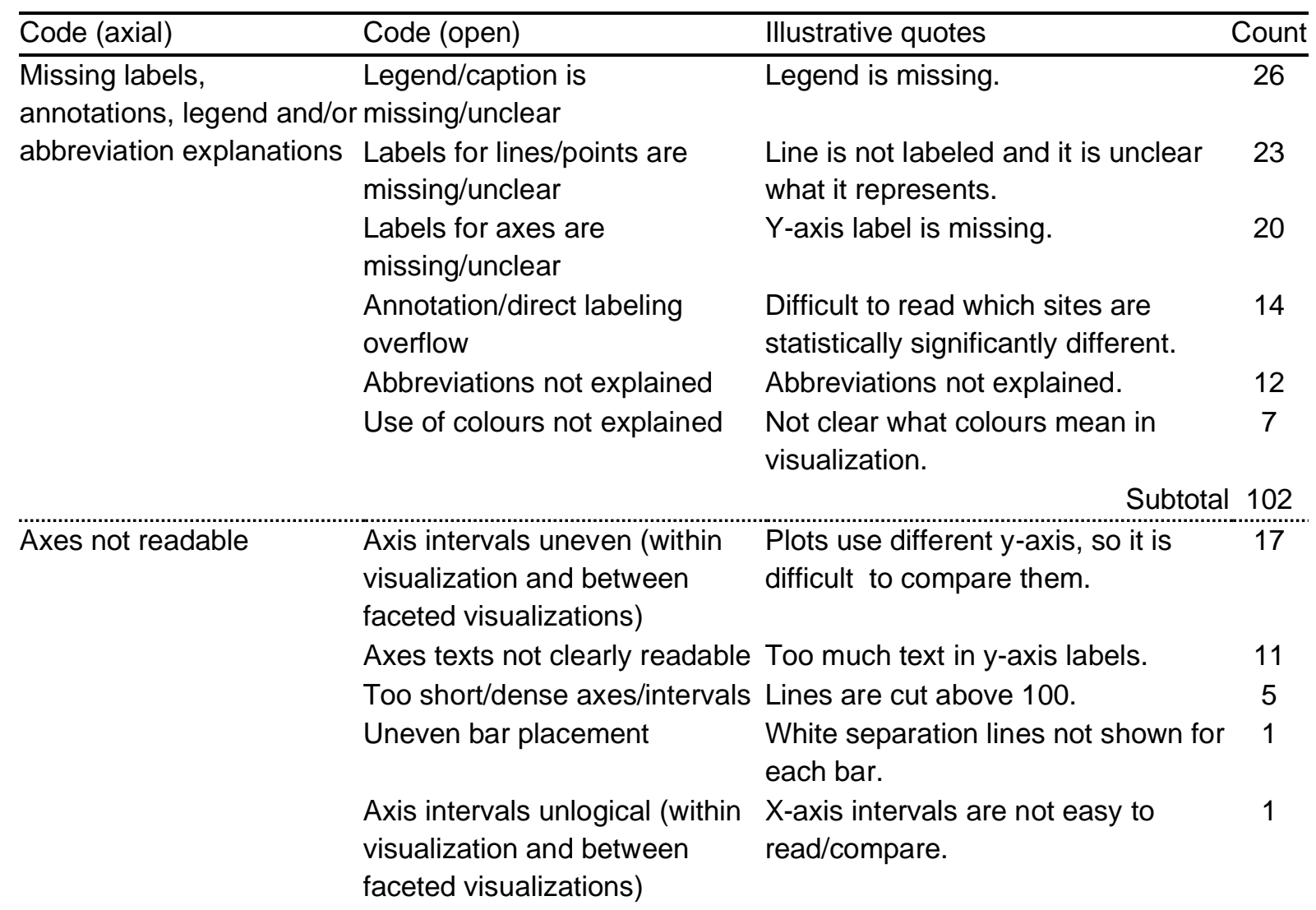

Subtotal 35

Colour scheme mismatch Groups not distinguishable by Use of similar colours, so hard to 14 


\begin{tabular}{|c|c|c|c|}
\hline & colours & distinguish. & \\
\hline & $\begin{array}{l}\text { Non-intuitive colour schemes } \\
\text { used }\end{array}$ & $\begin{array}{l}\text { Counter-intuitive coding (colour } \\
\text { luminance levels for min max should } \\
\text { be switched). }\end{array}$ & 6 \\
\hline & $\begin{array}{l}\text { Categorical colours used for } \\
\text { ordered attribute }\end{array}$ & $\begin{array}{l}\text { Mismatch of categorical colours for } \\
\text { order attribute. }\end{array}$ & 5 \\
\hline & $\begin{array}{l}\text { Groups not distinguishable } \\
\text { from background }\end{array}$ & $\begin{array}{l}\text { Colour for one group should not be } \\
\text { the same as background (white). }\end{array}$ & 2 \\
\hline & & Subtotal & 27 \\
\hline \multirow[t]{2}{*}{$\begin{array}{l}\text { Hidden data points by } \\
\text { overlaps }\end{array}$} & Overlap of shapes problematic & $\begin{array}{l}\text { Points could be double, but not } \\
\text { differentiable because of overlap. }\end{array}$ & 7 \\
\hline & & Subtotal & 7 \\
\hline \multirow[t]{3}{*}{$\begin{array}{l}\text { Using suboptimal channel } \\
\text { effectiveness }\end{array}$} & $\begin{array}{l}\text { Groups not distinguishable by } \\
\text { shapes }\end{array}$ & $\begin{array}{l}\text { Shapes are very difficult to } \\
\text { differentiate. }\end{array}$ & 12 \\
\hline & $\begin{array}{l}\text { Sub-effective channel is } \\
\text { chosen }\end{array}$ & $\begin{array}{l}\text { Shape/annotation not most effective } \\
\text { in distinguishing between } \\
\text { colonized/infected (colour higher } \\
\text { effectiveness) }\end{array}$ & 3 \\
\hline & & Subtotal & 15 \\
\hline \multirow[t]{4}{*}{$\begin{array}{l}\text { Size scale } \\
\text { indistinguishable }\end{array}$} & Differences in size not clear & $\begin{array}{l}\text { Standard errors difficult to read (too } \\
\text { small). }\end{array}$ & 10 \\
\hline & $\begin{array}{l}\text { Groups not distinguishable by } \\
\text { shape size }\end{array}$ & $\begin{array}{l}\text { Difference in study weight } \\
\text { (represented with square size) not } \\
\text { readable. }\end{array}$ & 3 \\
\hline & $\begin{array}{l}\text { Contrasts between groups not } \\
\text { clear }\end{array}$ & Difficult to follow one patient line. & 2 \\
\hline & & Subtotal & 15 \\
\hline \multirow[t]{3}{*}{ Missing channel } & $\begin{array}{l}\text { Line types not used to } \\
\text { distinguish between groups }\end{array}$ & $\begin{array}{l}\text { Different line types could improve } \\
\text { distinguishing the different groups. }\end{array}$ & 2 \\
\hline & $\begin{array}{l}\text { Colors not used to compare } \\
\text { between visualization/groups }\end{array}$ & $\begin{array}{l}\text { Colours could have been used to } \\
\text { make comparison of isolates across } \\
\text { groups easier. }\end{array}$ & 2 \\
\hline & & Subtotal & 4 \\
\hline $\begin{array}{l}\text { Visualization type does no } \\
\text { (optimally) fit data }\end{array}$ & $\begin{array}{l}\text { Other visualization type } \\
\text { preferred }\end{array}$ & $\begin{array}{l}\text { Too many categories for the plot } \\
\text { type (e.g. bar chart) would be } \\
\text { better). }\end{array}$ & 21 \\
\hline
\end{tabular}

\begin{tabular}{|c|c|c|c|}
\hline & & Subtotal & 21 \\
\hline \multirow[t]{2}{*}{$\begin{array}{l}\text { Data points/lines on } \\
\text { double axes }\end{array}$} & Double Y-axes difficult to read & $\begin{array}{l}\text { Double y-axis confuse (not easy to } \\
\text { apprehend which line is on which } \\
\text { axis). }\end{array}$ & 11 \\
\hline & & Subtotal & 11 \\
\hline \multirow[t]{5}{*}{ Channel overflow } & $\begin{array}{l}\text { Double use of shape and } \\
\text { colour }\end{array}$ & $\begin{array}{l}\text { Unnecessary use of two channels } \\
\text { for one attribute. }\end{array}$ & 8 \\
\hline & $\begin{array}{l}\text { Unnecessary use of shape } \\
\text { sizes }\end{array}$ & $\begin{array}{l}\text { Unequal size of point marks (without } \\
\text { meaning). }\end{array}$ & 1 \\
\hline & Unnecessary use of colour & $\begin{array}{l}\text { Unnecessary colour channel for } \\
\text { intervention period. }\end{array}$ & 1 \\
\hline & Too many colours & Too many colours. & 1 \\
\hline & & Subtotal & 11 \\
\hline \multirow[t]{2}{*}{ Attribute overflow } & Too many attributes & Plot is overloaded with attributes. & 2 \\
\hline & Relating attributes that are not & Stacked bar chart used for unrelated & 1 \\
\hline
\end{tabular}


bioRxiv preprint doi: https://doi.org/10.1101/2021.05.19.444819; this version posted May 20, 2021. The copyright holder for this preprint (which was not certified by peer review) is the author/funder, who has granted bioRxiv a license to display the preprint in perpetuity. It is made available under aCC-BY 4.0 International license.

related attributes (stacking does not make sense)

Subtotal 3

Information sparsity $\quad$ Could be text

Almost too little information.

Subtotal 1

Incoherent ordering

Data not ordered coherently

Colonized/infected not consequently 1 ordered in bars.

Subtotal 1

Grand Total 253 